We welcome letters to the Editor concerning articles which have recently been published. Such letters will be subject to the usual stages of selection and editing; where appropriate the authors of the original article will be offered the opportunity to reply.

Letters should normally be under $\mathbf{3 0 0}$ words in length, doublespaced throughout, signed by all authors and fully referenced. The edited version will be returned for approval before publication.

(C)2006 British Editorial Society of Bone and Joint Surgery

\$2.00 J Bone Joint Surg [Br] 2006;88-B6:838-40.

\section{Removal of acetabular bone in resurfacing arthroplasty of the hip}

Sir,

I read the article by Loughead et $\mathrm{al}^{1}$ in the January 2006 issue entitled 'Removal of acetabular bone in resurfacing arthroplasty of the hip: a comparison with hybrid total hip arthroplasty' with great interest, as the implantation of hip resurfacing represents a number of different technical challenges. An obvious one is appropriate implant sizing, permitting an appropriate press-fit of the acetabular component and avoiding damage of the femoral neck. In that respect, I believe that the conclusion of Loughhead et $\mathrm{al}^{1}$ that more bone is removed from the acetabulum in hip resurfacing is somewhat misleading. First and foremost, the authors failed to mention that the resurfacing implant used in this study is available in $4 \mathrm{~mm}$ increments on the femoral side, however implants from at least two other major manufacturers are sized in $2 \mathrm{~mm}$ increments. ${ }^{2}$ Thus, at the time of femoral component preparation, if one tentatively prepares the head to size $50 \mathrm{~mm}$, and the next size down is $46 \mathrm{~mm}$ and not $48 \mathrm{~mm}$, then a $46 \mathrm{~mm}$ component may become too small for the femoral neck, forcing the surgeon to use the $50 \mathrm{~mm}$-sized femoral component. Because of the necessary matching of the femoral and acetabular component in hip resurfacing, the femoral component sizing has a direct impact on acetabular component size. In addition, a prospective randomised trial comparing hip resurfacing with standard total hip replacement has demonstrated no difference in acetabular component size. ${ }^{3}$

Finally, the authors did not comment on their technique of femoral-head sizing and preparation in terms of removal or preservation of femoral head and neck osteophytes. If those osteophytes are not removed, the enlarged femoral head/neck junction will lead to the usage of a larger femoral component and subsequently a larger acetabular component. ${ }^{4}$

doi:10.1302/0301-620X.88B6.18083

\section{P. E. BEAULÉ, MD, FRCSC}

Associate Professor

University of Ottawa, Canada.

1. Loughead JM, Starks I, Chesney D, et al. Removal of acetabular bone in resurfacing arthroplasty of the hip: a comparison with hybrid total hip arthroplasty. J Bone Joint Surg [Br] 2006;88-B:31-4
2. Grigoris $\mathbf{P}$, Roberts $\mathbf{P}$, Panousis $\mathbf{K}$, Bosch H. The evolution of hip resurfacing arthroplasty. Orthop Clin North Am 2005;36:125-34

3. Lavigne M, Venditolli PA, Roy A. Prospective randomized clinical trial comparing metal on metal total hip arthroplasty and hip resurfacing in patients less than 65 years old. Osteologie 2005;14 (Suppl.II):80-3.[abstract]

4. Beaule PE, Antoniades J. Patient selection and surgical technique for surface arthroplasty of the hip. Orthop Clin North Am 2005;36:177-85.

Sir,

I read this article with interest. It confirms the widely-held impression that resurfacing hip arthroplasty may not be conservative in relation to acetabular bone when compared with hybrid hip replacement. The results coincide with similar evidence published elsewhere. ${ }^{1}$

Loughead et $\mathrm{al}^{2}$ recommend using the smallest femoral component compatible with the avoidance of femoral notching to minimise the extent of acetabular bone resection. Such narrow margins, if widely applied, may result in a certain number of cases of notching, with possible damage to the blood supply to the femoral head. ${ }^{3}$ Moreover, it has been suggested by Amstutz et $\mathrm{al}^{4}$ that small components in male patients may predispose to early revision.

Too much emphasis may have been given to the issue of bone conservation on the acetabular side in hip resurfacing, and recent designs incorporating thinner (more conservative) acetabular shells have resulted in an increased number of early revisions. ${ }^{5}$ Accurate templating and selection of implants may be the most appropriate course to take. It should be remembered that revision of hip resurfacing more commonly involves the femoral side only and patterns of osteolysis and further bone destruction are not comparable with those seen following the use of cementless acetabular components with polyethylene liners in hybrid hip arthroplasty.

doi:10.1302/0301-620X.88B6.18084

R. F. SPENCER, MD, FRCS,

Weston General Hospital,

Weston-super-Mare, UK.

1. Crawford JR, Palmer SJ, Wimhurst JA, Villar RN. Bone loss at hip resurfacing: A comparison with total hip arthroplasty. Hip International 2005;15:195-8.

2. Loughead JM, Starks I, Chesney D, et al. Removal of acetabular bone in resurfacing arthroplasty of the hip: a comparison with hybrid total hip arthroplasty. J Bone Joint Surg [Br] 2006;88-B:31-4.

3. Beaule PE, Campbell PA, Hoke R, Dorey F. Notching of the femoral neck during resurfacing arthroplasty of the hip. J Bone Joint Surg [Br] 2006;88-B:35-9.

4. Amstutz HC, Beaule PE, Dorey FJ, et al. Metal-on-metal hybrid surface arthroplasty:Two to six-year follow-up study. J Bone Joint Surg [Am] 2004;86-A:28-39.

5. Australian Orthopaedic Association National Joint Registry 2005.

Sir,

We read this article with interest. The authors conclude that more acetabular bone is removed during a surface replacement arthroplasty (SRA) than during a THA. The retrospective nature of the study and the patient selection for SRA, which includes more males with a different femoral pathoanatomy, may have biased their conclusion. To be able to compare the two groups, they used 
the femoral head diameter of the contralateral side for correction of size. This is not appropriate, as the contralateral side often has different pathoanatomy when compared with the operated side. Secondly, the limiting factor in hip resurfacing is the femoral neck diameter, not the femoral head diameter. We believe that 'resurfacing patients' are so different from 'standard THA patients' that a comparative study (the same surgeon operating on the patients during the same time period) is not accurate enough to address the question of bone resection adequately.

In this study several factors may have influenced the amount of resection of acetabular bone, including the design of femoral and acetabular components and the increments of size of the implant system. When upsizing the femoral component, which may occur to avoid femoral neck notching, the larger the increment $(4 \mathrm{~mm}$ for Birmingham hip replacement), the more bone will be sacrificed on the acetabular side. The thickness of the acetabular component wall is important, since for a given femoral component size, the thicker the acetabular component, the more bone that needs to be removed. Surgical technique is also a major factor affecting the removal of bone. Successfully implanting a resurfacing implant is not simply an issue of obtaining fixation, good position and avoiding notching, surgeons rightly concerned about preserving femoral bone stock should also be concerned about preservation of acetabular bone stock.

doi:10.1302/0301-620X.88B6.18085

P.A. VENDITTOLI, MD, MSc, FRCS, Assistant Professor of Surgery, M. LAVIGNE, MD, FRCS

A.G. ROY, MD, FRCS

J. GIRARD, MD

Hopital Maisonneuve-Rosemont, Canada.

Sir,

We read this article with interest. We fully agree with the authors that oversizing of the femoral component, which leads to oversizing of the acetabular component, must be avoided at the time of hip resurfacing. However, we believe it is misleading to imply that excessive acetabular removal of bone is a generic problem in a hip resurfacing procedure.

The size of the components used is dependent not only on the morphology of the head/neck junction, but also on specific design features of the prosthesis, and on the surgical technique and philosophy with which it is implanted. Critical factors include the wall thickness of both components and the available size increments. These vary between different manufacturers. ${ }^{1}$ With respect to surgical technique, it is essential to be able to accurately and reproducibly prepare the femoral head to allow the use of the smallest possible femoral component without notching the femoral neck, particularly in cases with extensive neck re-modelling and/or osteophyte formation. This is facilitated by the use of sophisticated femoral instrumentation which allows accurate positioning of the cylinder cut, avoiding notching which may lead to a neck fracture post-operatively. If there is an extremely abnormal anatomy of the femoral head/neck junction, femoral and acetabular oversizing would be necessary, therefore it may be more appropriate to resect the femoral head and convert to a stemmed total hip replacement rather than sacrificing valuable acetabular bone stock. doi:10.1302/0301-620X.88B6.18086

P. ROBERTS, MA, FRCS, Orthopaedic Surgeon,

P. GRIGORIS, PhD, FRCS

Royal Gwent Hospital,

Newport, UK.
1. Grigoris $\mathbf{P}$, Roberts $\mathbf{P}$, Panousis $\mathbf{K}$, Jin ZM. Hip resurfacing arthroplasty. The evolution of contemporary designs. J Eng Med 2006; in press.

\section{The premature failure of the Charnley Elite-Plus stem}

Sir,

I read the article by Hauptfleisch et $\mathrm{al}^{1}$ in the February 2006 issue entitled 'The premature failure of the Charnley Elite-Plus stem: a confirmation of RSA predictions' with interest and would like to add my comments.

The authors do not describe failure of the Charnley Elite-Plus stem, they describe failure of fixation of this stem. The distinction is essential if the source of the problem is to be identified and addressed. They are not correct when quoting our publication ${ }^{2}$ "...design included a modification of the shoulder flange to reduce subsidence ...". "The dorsal flange was intended to make the upper level of cement function more efficiently in load transmission." 3

The Charnley Elite-Plus stem has a different history. In their surgical technique no mention is made of clearing the calcar ${ }^{4}$ or the position of the stem within the medullary canal. The importance of the direction of the load out of plane of the neck of the stem $^{5}$ or the femur ${ }^{6}$ has been highlighted. These are, however, minor points.

The most worrying is their statement: "Ethical approval for the follow-up study was obtained and the patients were contacted...". Does this mean that the authors did not follow up their patients even when they "predicted that overall, the implant would have a high rate of failure" ? Why was ethical approval needed to follow up patients? Is this not normal practice? If that is the case, who should bear the continuing burden of clinical, moral, financial and legal responsibility for regular monitoring of the results, other than by "...peri-prosthetic fracture which was deemed to be secondary to the loosening"?

doi:10.1302/0301-620X.88B6.18087

B. M. WROBLEWSKI, Consultant Orthopaedic Surgeon, The John Charnley Research Institute, Wrightington Hospital, Wigan, UK.

1. Hauptfleisch J, Glyn-Jones S, Beard DJ, Gill HS, Murray DW. The premature failure of the Charnley Elite-Plus stem: a confirmation of RSA predictions. J Bone Joint Surg [Br] 2006;88-B:179-83.

2. Wroblewski BM, Fleming PA, Hall RM, Siney PD. Stem fixation in the Charnley low-friction arthroplasty in young patients using an intramedullary bone block. J Bone Joint Surg [Br] 1998;80-B:273-8.

3. Charnley J. Low friction arthroplasty of the hip. Theory \& Practice. Berlin; SpringerVerlag, 1979:126.

4. Wroblewski BM, Siney PD, Fleming PA, Bobak P. The calcar femorale in cemented stem fixation in total hip arthroplasty. J Bone Joint Surg [Br] 2000;82-B. 842-5.

5. Wroblewski BM. The mechanism of fracture of the femoral prosthesis in total hip replacement. Int Orthop 1979;3:137-9.

6. Wroblewski BM. Transverse load on the hip joint: a subject for further research. Engineering in Medicine 1980:9:163-4.

7. Alfaro-Adrian J, Gill HS, Murray DW. Should total hip arthroplasty femoral components be designed to subside? A radiostercometric analysis study of the Charnley Elite and Exeter stems. J Arthroplasty 2001;16:598-606.

\section{Authors' reply,}

We thank Professor Wroblewski for his interest in our article and for his comments.

With regard to the direction of load, we actually consider this to be the major point; rotation is an important mechanism of failure 
for cemented total hip stems and rotation is due to loads acting perpendicular to the plane containing the neck and the stem. We feel that rotational stability is an important feature of forgiving cemented total hip stem designs.

Failure of fixation of total hip stems is a consequence of a number of factors: the stem design, the implantation technique, and the patient. In our earlier article ${ }^{1}$ we attempted to reduce the number of variables by standardising the technique and selecting similar patient groups, and the evidence would suggest that failure of fixation in this case is associated with the stem design.

With respect to the design rationale of the modification of the shoulder flange, the aim of making the "cement function more efficiently in load transmission" is to prevent loosening of the stem. As loosening is manifested by subsidence, we are confused as to why Professor Wroblewski considers our phrase to be incor- rect. We described the surgical technique in our previous publication. ${ }^{1}$

Professor Wroblewski raises an important point concerning follow-up. We asked our local research ethics committee (LREC) for advice prior to commencing this study, and we were told that we needed to submit an application and seek LREC approval.

Again, we thank Professor Wroblewski for his interest and his comments.

doi:10.1302/0301-620X.88B6.18088

D. W. MURRAY, Professor of Orthopaedic Surgery, H. S. GILL, University Research Lecturer,

Nuffield Orthopaedic Centre,

Oxford, UK

1. Alfaro-Adrian J, Gill HS, Murray DW. Should total hip arthroplasty femoral components be designed to subside? A radiostereometric analysis study of the Charnley Elite and Exeter stems. J Arthroplasty 2001;16:598-606. 